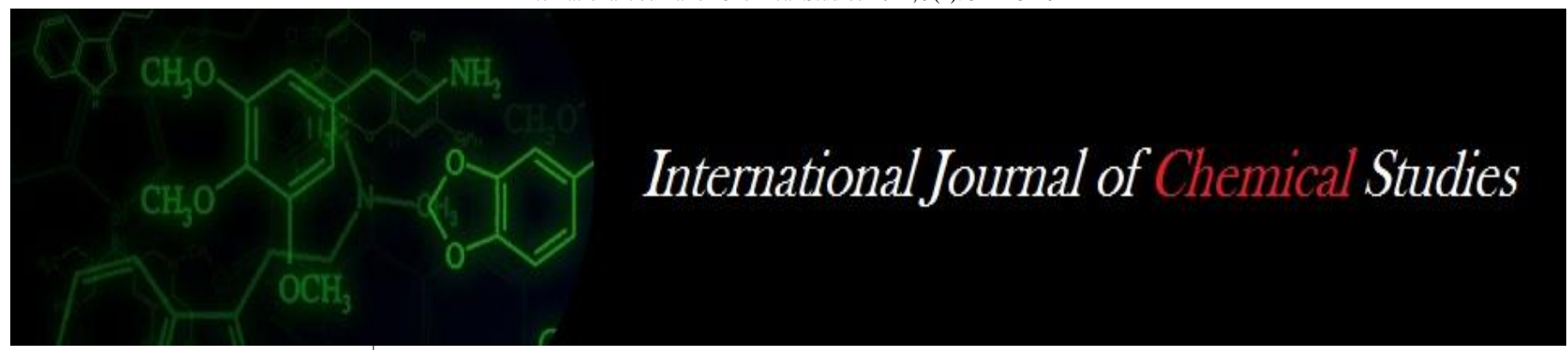

P-ISSN: 2349-8528

E-ISSN: 2321-4902

www.chemijournal.com

IJCS 2021; 9(1): 3224-3229

(C) 2021 IJCS

Received: 09-11-2020

Accepted: 16-12-2020

\section{RV Mahajan}

Anand Niketan College of

Agriculture, Warora Dr.

Panjabrao Deshmukh Krishi

Vidyapeeth, Akola,

Maharashtra, India

\section{SB Amarshettiwar}

Anand Niketan College of

Agriculture, Warora Dr.

Panjabrao Deshmukh Krishi

Vidyapeeth, Akola,

Maharashtra, India

\section{ND Gajbe}

Anand Niketan College of

Agriculture, Warora Dr.

Panjabrao Deshmukh Krishi

Vidyapeeth, Akola,

Maharashtra, India

\section{SP Wagh}

Anand Niketan College of

Agriculture, Warora Dr.

Panjabrao Deshmukh Krishi

Vidyapeeth, Akola,

Maharashtra, India

\section{RV Tayade}

Anand Niketan College of

Agriculture, Warora Dr.

Panjabrao Deshmukh Krishi

Vidyapeeth, Akola

Maharashtra, India

\section{Corresponding Author:}

\section{RV Mahajan}

Anand Niketan College of

Agriculture, Warora Dr.

Panjabrao Deshmukh Krishi

Vidyapeeth, Akola,

Maharashtra, India

\section{Madhuka: Promising millennium plant}

\author{
RV Mahajan, SB Amarshettiwar, ND Gajbe, SP Wagh and RV Tayade
}

DOI: https://doi.org/10.22271/chemi.2021.v9.i1as.11727

\begin{abstract}
Mahua is one of the most important Indian forest trees because of its delicious and nutritive flowers with abundant vegetative growth. Mahua is one of the important tree species in central India, as it produces abundant delicious and nutritive flowers. Mahua, the Indian Butter Tree is an important tree having vital socioeconomic value and growing throughout the tropical and subtropical region of the Indian subcontinent. It is fast growing tree that grow upto approximately 20 meter height, possesses evergreen or semi evergreen foliage with wider and round canopy. It belongs to family Sapotaceae. The tree is considered a boon by the Tribal's who are the forest dwellers and keen conservator of the tree. Mahua provides livelihood security to poor households who collect it both for self consumption and for sale the income is used to purchase daily household item. It provide them food, medicine, feed and medicine for their livestock apart from its miscellaneous utilities. Mahua flowers are well known for their high reducing sugar and nutrient content. Flowers of the plant are edible. The flowers are used to produce an alcoholic drink in several parts of India. The fruit pulp may be utilized as source of sugar, whereas the dry husk makes a good source of alcoholic fermentation. Seed is serves as an important fuel oil, hence a good source of biodiesel. Its oil is used by tribal as vegetable butter in addition it is used in skin care products, soaps, detergents, etc. The seed cake is used as manure. The tribes consider the mahua tree and the mahua drink as part of their cultural heritage. So it is very much necessary to create awareness among the people to conserve the forest.
\end{abstract}

Keywords: Madhuka, butter nut tree, Sapotaceae, traditional uses and tribes

\section{Introduction}

Mahua is a large deciduous tree growing widely under dry tropical and sub tropical climatic conditions. Madhuca Longifolia distributed in Andhra Pradesh, Gujarat, Madhya Pradesh, Odisha, Chhatisgadh, Jharkhand, Bihar, Uttar Pradesh. Mahua (Madhuca indica J.F. Gmel. syn. Madhuca latifolia Macb.) belonging to the family Sapotaceae, is one of those multipurpose forest tree species that provide an answer for the three major Fs i.e. food, fodder and fuel. It is widely distributed in the South Asian countries (Banerji and Mitra, 1996). It is an important tree for poor, greatly valued for its flowers and its seeds known as tora. The tree has religious and aesthetic value in the tribal culture.

The trees with best girth in forest are often Mahua trees as it is protected and cared by forest dwellers. Mahua tree can be found in forests, revenue, and private land. The early settlers had rights to specific Mahua trees occurring near the village in private, revenue and forestlands. Some trees may even be located at long distance from the village but are recognized as being associated to a family. These rights are only for harvesting flowers but not for fruits and have been practiced. These rights have passed from generation to generation. When father divides the property among his sons, he also divides Mahua tree between them but keeps some for himself till the end, as it becomes an easy source of income. In absence of sons, harvesting rights are given to daughters when they get married. Sometimes villagers of one region, in dearth of Mahua, visit relatives who have trees in abundance. (Mishra Sunita \& Padhan Sarojini 2013) ${ }^{[14]}$.

Jayasree et al., (1998) ${ }^{[8]}$ find out that, the tree, known under the name of mahua, produces edible flowers and fruits. The leaves of Mahua tree contain saponin, an alkaloid glucoside. Sapogenin and other basic acid have been found in the seeds. Mahua flowers are well known for their high reducing sugar and nutrient content. They are edible and used as a sweetener in preparation of many local dishes like halwa, Kheer, Puri and burfi (Patel and Naik, 2008) ${ }^{[16]}$ in the Mahua production belt of India. 
However, due to the lack of proper scientific investigation and post harvest processing technologies, they are collected and subjected to open yard sun drying till about $80 \%$ moisture is lost, before storage (Patel and Naik, 2008) ${ }^{[16]}$.

This process results in heavy microbial load and degrades their food value, finally making them suitable only for the liquor distillation units and as cattle feed. This way a precious, organic and easily available source of natural sugar is being under-utilized. According to Sahay and Singh, (1996) Mahua is one of the most important forest trees because of its delicious and nutritive flower with abundant vegetative growth. $\mathrm{t}$ is fast growing tree that grow upto approximately 20 meter height, possesses evergreen or semi-evergreen foliage with wider canopy.

It belongs to family Sapotaceae. It cultivated in warm region for its oleaginous seed. Its oil (solid at ambient temperature) is used for care of skin, used for manufacture of soaps, detergents and as vegetable butter. It can be used as fuel oil. The seed cake obtain after extraction of oil is used as very good fertilizer.

The flower is used for its medicinal properties. It considered as holy tree by many tribal communities because of its usefulness. The bark is used for medicinal purposes. The tree is considered a boon by the Tribal who are forest dwellers and they are keen conservation of this tree.

However, the conservation of the tree has been marginalized as it is stated that the non-tribal do not favour propagation of this tree.

\section{Botanical Distribution}

Mahua is a medium sized to large deciduous tree, usually with a large rounded crown found up to an altitude of 1,200 meter and of 12 to 15 meter height. Bark grey to black with cracks, inner bark dark red, milk, trunk short, branches numerous (Behl and Sriwasrawa, 2002) [3]. Mahua tree has large spreading root system, through many of them are superficial. Wood is hard to very hard with large sapwood. Hardwood is reddish brown colour. It is a large and deciduous tree with short bole and rounded crown. Its bark thick green to black with vertical cracks wrinkled. Leaves oblong shaped, rigid clustered at the end of branches, $6-9 \mathrm{~cm}, 13-23 \mathrm{~cm}$, thick and firm exuding a milky sap when broken. Young leaves are pinkish and wooly underneath. Leaves are thick, leathery, pointed at the tip and clustered at the end of branches. Flower are cream coloured fleshy, juicy, clustered at end of branches. Fruits ovoid, fleshy, greenish, $3-5 \mathrm{~cm}$ long, elliptical, flattened on one side. Most of the leaves fall from February to April and during that time the musky-scented flower appears. Through small eyelet holes at the top. A couple of month after the flowering period, the fruit open. The fruit is a kind of berry, egg shaped. Mature seeds can be obtained during June to July. Mahua is slow growing species, attains a mean height of 3 to 4 feet at the end of fourth year (Kureel et al., 2009) ${ }^{[13]}$. The two major species of genus Madhuka found in India are Madhuka Indica (syn. Bassia latifolia) and Madhuka longifolia (Syn Basia longifolia). Mahua is widely accepted as a local name (Kureel et al., 2009) ${ }^{[13]}$. The regional names in some potential states are

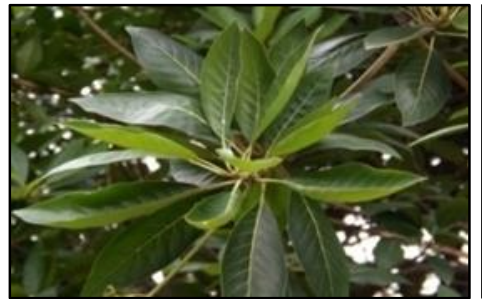

a) Mahua leaf

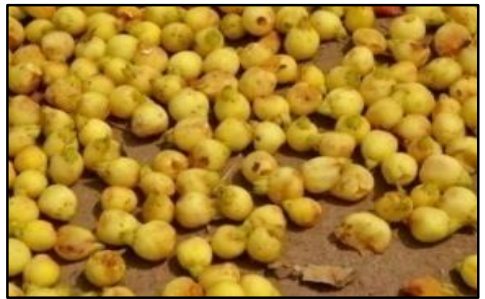

b) Mahua flower

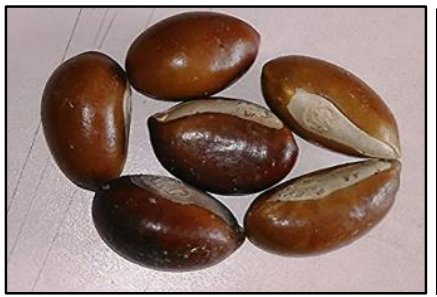

c) Mahua fruit

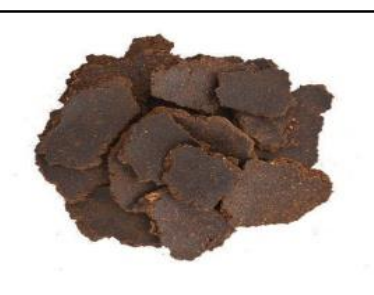

d) Mahua cake

$\begin{array}{lll}\text { State } & \text { Regional names } & \text { Scientific } \\ \text { Andhra Pradesh } & \text { Ippe, Yappa } & \text { Kingdom } \\ \text { Gujrat } & \text { Mahuda } & \text { Division } \\ \text { Karnataka } & \text { Hippe } & \text { Class } \\ \text { Kerala } & \text { Ponnam, Ilipa } & \text { Order } \\ \text { Maharashtra } & \text { Mahwa, Mohwara } & \text { Family } \\ \text { Orissa } & \text { Mahula, Moha, Madgi } & \text { Genus } \\ \text { Tamil Nadu } & \text { Illupi, Elupa } & \text { Species } \\ \text { Hindi } & \text { Mahua, Mohwa, Mauwa } \\ \text { English } & \text { Butter tree } & \\ \text { Sanskrit } & \text { Madhuka } & \end{array}$

Classification

Plantae

Magnoliaphyta

Mangnoliopsida

Ericolos

Sapotaceae

Madhuca

Indica (syn. Bassia latifolia) Lomgifolia (syn. Bassia latifolia)

\section{Origin and Distribution}

The mahua introduced from India to Australia and Polynesia (Troup, 1921; Anon. 1988). The species Madhuca longifolia is distributed in northern, central and southern part of peninsular India, and M. latifolia is found in some parts of central and north India. Mahua is a deciduous tree of dry region and native of India.

A Multipurpose tree, mostly grown on wasteland in North and Central part of country where generally tropical and subtropical climates prevail. It grown in Eastern Uttar Pradesh, Chhattisgarh, Maharashtra, Bihar, Jharkhand, Odisha and Andra Pradesh. Madhuka latifolia ia a medium sized to large deciduous tree, distributed in Andhra Pradesh, Gujarat,

Madhya Pradesh, Odisha, Bihar and Uttar Pradesh. Madhuca longifolia is a large evergreen tree found in South India and in the evergreen forest of Western Ghats from Konkan Southwards.

\section{Ecology}

Mahua grown well on a wide variety of soil especially on alluvial soil in Indo-gangetic plain. Mahua being hardy thrives well on rocky, gravelly red soil and also on saline and sodic soils. It grown even in pockets of soil between crevices of barren rock.

For its better growth and productivity, well deep loam or sandy -loam soil with good drainage are ideal. It also occurs 
on shallow bounder clayey and calcareous. Mahua prefers tropical and subtropical climate. It withstands drought admirably. Mahua grown upto an altitude of $1200 \mathrm{~m}$, mean annual temperature $2-46^{\circ} \mathrm{C}$ and mean annual rainfall ranging from $550-1500 \mathrm{~mm}$.

\section{Flowering and Fruiting}

In Mahua flowers appear just leaf fall (February to April) in different agro-climatic zone of the country. Time taken for complete development of flower bud from its visible initiation anthesis varies from 20 to 30 days. Singh et al. (2006) recorded that the peak period of flowering and fruit set commenced in the month of March and April in different genotypes. M. latifolia is Longlived and starts bearing from about the $10^{\text {th }}$ year. A full grown tree can produce up to $90 \mathrm{~kg}$ of flowers in a year.

The mahua flower is edible and is a food item for tribal 's. These flowers are then collected in bamboo baskets mostly by tribal women and children. Flowers are then spread on pre cleaned ground for sun drying.

During this process flowers shrink in size and turn reddish brown in colour. The characteristic odour increases after drying of flowers. These flowers are sweet in taste and have characteristic flavour. The tribals then store some of the mahua flowers for their own consumption and sell the rest of dried flowers in local market.

\section{Harvesting}

Maturity of mahua depends upon the genotype and different environmental condition. Mahua fruit growth was very faster at starting period and thereafter slower down upto the maturity. The biochemical proper property of mahua fruit such as Total Soluble Solid (TSS), total and reducing sugar increased during fruit development and decreased thereafter.

Harvesting of mahua fruit starting in month of May and June, ideal time of fruit harvesting is 3 rd weed of May to $3^{\text {rd }}$ week of June. Seed are obtained from ripe fruit. The kernel of mahua after shelling and kernel dried upto lowest moisture content i.e. 6\% Dried kernel can be use for oil extraction process.

\section{Yield}

The yield of mahua plant depends upon environmental condition, tree size, age of tree and local condition. Mahua yield both flower and seeds, Variation was observed in mahuva flower and mahua fruit. Mahua tree produce dry flower yield varies from $100-150 \mathrm{~kg} /$ tree/year and mahua seed kernel gives 60-80 kg/tree/year (Kureel et al., 2009) ${ }^{[13] .}$

Table 1: Traditional uses of Madhuca longifolia in India

\begin{tabular}{|c|c|c|c|}
\hline Sr. No. & Tree parts & Medicinal use & References \\
\hline 1 & Seed cake & Anti-inflamatory, anti ulcer and hypoglycaemic activity & Seshagiri M. et al 2007 \\
\hline 2 & Bark & Ant diabetic activity & K Pavan Kumar et al. 2011 \\
\hline 3 & Bark & Antioxidant activity & Samaresh Pal Roy et al. 2010 \\
\hline 4 & Flower & Analgesic activity & Dinesh Chandra et al. 2001 \\
\hline 5 & Leaves and bark & Wound healing activity & Smita Sharma et al. 2010 \\
\hline 6 & Leaves & Nephro and hepato protective activity, antioxidant and cytotoxic activity & S. Palani et al. 2010 \\
\hline 7 & Leaves & Antimicrobial activity & Mangesh Khond et al. 2009 \\
\hline 8 & Flower & Skin disease & Srirangam Prashanth et al. 2010 \\
\hline 9 & Flower & Cure cough & S. Palani et al. 2010 \\
\hline 10 & Fruits & Asthama & S. Palani et al. 2010 \\
\hline 11 & Leaves and stem & Antimicrobial activity & Mangesh Khond et al. 2009 \\
\hline 12 & Seeds & Effective to alleviate pain & Srirangam Prashanth et al. 2010 \\
\hline
\end{tabular}

\section{A) Potential uses of mahua}

1) Mahua flower: Stored quality of mahua flowers depend on the need of the family. The poorer the family is the storage. Usually, the tribal's do not store these product for long, as they generate the earnings to them especially during lean period and secondary Mahua flowers being hygroscopic, absorb atmospheric moisture and get spoiled. The flowers of Mahua are fermented to produce an alcoholic drink called Mahua, country liquor. Mahua drink is considered as part of their cultural heritage. Tribal people men and women consume this drink and is an obligatory item during celebration and evening activities.

2) Mahua fruits: Fruits of mahua are also utilized for human consumption as food. Unripe fruits are used for vegetable preparation. Flesh of mahua fruit covering hard seeds are first peeled off to remove outer thin portion and then remaining portion are cut into pieces and fried in small amount of mustard oil along with onion and garlic paste. Take a appropriate amount of mixed spices powder and cook till complete softening of fruit pieces and also prepare a concentrated curry of mixed spices. Berries are eaten raw or cooked. Fruits are astringent and can be used as a lotion in chronic ulcers. Consumption of fruits is known to cure blood diseases (Siddiqui et al.,2004; Awasthi et al., 1975) ${ }^{[2]}$.

3) Mahua seed oil: Mahua seeds contain about $40 \%$ pale yellow semi-solid fat. The seed oil is commonly known as Mahua Butter. The oil content of the seed varied from 33 to $43 \%$ weight of the kernel. Fresh Mahua oil from properly stored seeds is yellow in colour with a not unpleasant taste. The oil is used as cooking oil by most of the tribes in India. The oil solidifies to a buttery consistency and hence tree is also known as "The Indian Butter Tree". The oil is used for edible and cooking purpose. It is one of the ingredients of hydrogenated vanaspati. It is also used in the manufacture of soaps, particularly laundry chips. It is also used as illuminant and hair oil, especially in rural parts in India. (Kureel et al., 2009) ${ }^{[13]}$.

Table 2: Nutritional and Characteristic aspects of Mahua

\begin{tabular}{|c|c|c|c|c|c|}
\hline \multicolumn{2}{|c|}{ Nutritional aspects of Mahua flower } & \multicolumn{3}{c|}{ Characteristic of Mahua seed oil } \\
\hline Sr. No. & Constituents & Flower & Sr. No & Properties & Value \\
\hline 1 & Moisture (\%) & 19.8 & 1 & Refractive index & $1.452-1.462$ \\
\hline 2 & Protein (\%) & 6.37 & 2 & Saponification value & $1.87-1.97$ \\
\hline
\end{tabular}




\begin{tabular}{|c|c|c|c|c|c|}
\hline 3 & Fat (\%) & 0.5 & 3 & Iodine value & $55-70$ \\
\hline 4 & Reducing Sugar (\%) & 50.62 & 4 & Unsaponification matter (\%) & $1-3$ \\
\hline 5 & Total Inverts (\%) & 54.24 & 5 & Palmitic C 16:0 (\%) & 24.5 \\
\hline 6 & Cane Sugar (\%) & 3.43 & 6 & Steric acid C 18:0(\%) & 22.7 \\
\hline 7 & Total sugar (\%) & 54.06 & 7 & Oleic acid C (18.2)\% & 22.7 \\
\hline 8 & Ash (\%) & 4.36. & 8 & Linolic acid C 18:2(\%) & 14.3 \\
\hline 9 & Calcium (ppm) & 8 & & & \\
\hline 10 & Phosphorus (mg/lit) & 2 & & & \\
\hline
\end{tabular}

4) Oil cake: Seed oil cake is having very good insecticidal properties. It is also used as organic manure and soil amendments. It is truly organic manure which enhances the fertility of the soil. Improve the physical, chemical and biological properties in soil. Mahua cake is supply the primary, secondary and micronutrients for crop growth. It can be combined with any nitrogenous fertilizer for better results and urea to prevent the loss of nitrogen due to leaching \& microbial action.

5) Biodiesel: The oil content of the seed varied from 33 to $43 \%$ weight of the kernel for the tribal's of India, Mahua oil is by far the most important tree seed oils. This is extracted by Ghani or Expeller. Bio-diesel (Mahua Oil Methyl Ester) prepared from seed oil by transesterification process followed by esterification. Transesterification is a process of producing a reaction in triglyceride and alcohol in presence of catalyst to produce glycerol and ester. Transesterifications a fat or oil is mixed with an alcohol to form methyl esters known as biodiesel and glycerol. During the reaction completion the oil to Mahua oil methyl ester (Bio-diesel) is checked by using thin layer chromatography (TLC) technique (in various time intervals) (Puhan el al 2005)

6) Self-reliant economy: Mahua tree is boon for the tribal economy with various benefits in the form of therautic, culinary, staple, cattle feed as well as liquor production. Next intensification of all potential medicinal and non-medicinal uses of Mahua, plant is serving by tribal people of India, providing an open opportunity for them. Mahua flowers collection is an important source of employment to the poor people living in rural and tribal areas. Collection of flower, fruits and seed mahua scores higher in tribal areas which has multiple utilities. They are used for consumption as well as local sale.

\section{B) Medicinal Uses}

1) Anti-Inflammatory Effect: Inflammation is a complex response of a body to the external stimuli. Formation of inflammatory leukcocytes in this process leads to the excess generation of free radicals which alters the cellular function and damages the organs by initiating and promoting the various diseases. Several scientific studies on the ethanolic extract of Madhuca bark and seeds had proven antiinflammatory activity. The crude ethanolic extract, saponin mixture and methanolic bark extract of $\mathrm{M}$. longifolia extract has shown significant effect on inflammation induced by carrageenan as followed by the study of Agrawal et al. and Gaikwad et al.

2) Antidiabetic Activity: Madhuca indica has also shown its effectiveness as an antidiabetic. Methanolic extract of the leaves and bark of this plant has been studied in streptozotoc in-induced diabetes in male albino Wistar rat, and the result was compared with the standard insulin-treated rat.

3) Antimicrobial Activity: The alcoholic extract of leaves and flowers of Madhuca longifolia were screened for antimicrobial activities against Staphylococcus aureus, Bacillus subtilis, Escherichia coli, Pseudomonas aeruginosa, Aspergillus oryzae and Aspergillus niger. In general, commercial antibiotic and antifungal drugs causes side effects. However, herbal remedies often do not produce any side effects. Therefore, alternative medicine become popular remedy to various types of ailments In conclusion, Madhuca longifolia extracts have revealed significant antimicrobial activities against test organisms used for the study (Kalaivani.M and M. Jegadeesan, 2013)

4) Wound healing activity: Investigation of Sharma et al. 2010 deduced the notable wound healing property of Madhuca as compared to standard betadine. This activity may be due to the presence of constituents responsible for the promotion of wound healing. In this study,ether-benzene-95\% crude ethanolic extract of leaves and bark of M. longifolia showed a marked reduction in wound healing time with respect to control in excision wound model. There was a significant increase in the rate of wound closure and epithelisation rate (Jha and Mazumder, 2018) ${ }^{[9]}$.

5) Anti-ulcer activity: Peptic ulcer is chronic inflammatory condition referring to the sores and ulcer in the lining of stomach and duodenum (Shirode et al., 2010). Experimental works of Kalaivani and Jegadeesan had shown that ethanolic extract of bark possess significant antiulcer action. Study of Mohod and Bodhankar had proven the antiulcer activity of aqueous extract of leaves. The crude ethanolic extract of seeds of Madhuca showed significant protective effect in pylorus ligation induced gastric ulcer model with a marked decrease in ulcer index as compared to vehicle.

\section{C) Use of Mahua as a food}

Mahua plays an important role in the social life and economy in tribals in India. Mahua can fulfil the basic requirements such as food, fruit, fodder and fuel for survival.

1) Halwa: Fresh collected flowers are crushed to extract the juice which is used as substitute of sugar syrup to prepare halwa of wheat flour.

2) Sweet Puri: Dried flower are soaked in water for the three to four hours and excess water decanted. Pre soaked dried flowers are grounded well to prepare a paste. Thus prepare paste are now mixed with equal amount of fine wheat flour to prepare a tight dough. Now small bread sized puries are prepared and baked first dry and subsequently deep fried either in mahua oil or mustard oil or as per taste of individual.

3) Gulgule: Method of preparing gulgule is similar to sweet puri, but only difference is that the dough prepared for this purpose remains very loose and soft so that the rounded ball shaped dough is deep fried in mahua oil, mustard oil, deshi ghee or vegetable oil. 
4) Edible oil: Mahua seed contain high percentage of edible oil used for cooking purpose. Linoleic acid is major unsaturated fatty acid found in pure oil which helps to reduce cholesterol level and thus used for preparation of vegetable oil, grease, soaps and candle. Oil is also used for lightening lamps in rural areas. The oil is used mostly in soap making, treatment of wool and jute for candle making, for edible purpose by tribal people. It is also used in medicine for skin disease. The oil has potential to reduce serum cholesterol levels owing to the presence of oleic and linoleic acids (PUFA). Mahua oil has been beneficial in the cure of skin diseases, bilious fevers, rheumatism and burning sensation. The seed oil has quality of softening or soothing the skin (Awasthi et al., 1975) ${ }^{[2]}$.

5) Sugar syrup: There are several reports on preparation of sugar syrup from dry Mahua flowers, as its sweet property is utilized in the fermentation process. The water extract of dried flower is decolorized with different de colorizing agent like slacked lime and activated charcoal before concentrating it to the desired concentration. Activated charcoal at a concentration of $3.5-5 \%$ was found to be the best agent for the preparation of the Mahua sugar syrup (Patel et al 20101) ${ }^{[17]}$. The syrup thus obtained from the flower of Mahua is employed in the different purpose, either in the manufacturing of chocolate or as a sweetening agent.

\section{D) Common uses of mahua}

1) Timber: Wood of mahua is not widely used as the tree is highly useful for its flower, fruit and oil. Old Mahua tree is usually cut down for tree uses. Seasonal wood is used for door frame in house, building, furniture and country vessels and wheels of bullock pair. Tree bark contains 17 percent of tannin which is used for dyeing. Barks are also reported to heal wounds. Young succulent and tender branches are also used for brushing and cleaning teeth (Datun) in morning hours.

2) Fodder: The leaves of mahua are of very high nutritive value for cattle, goat and sheeps. Trees are lopped for fodder in almost every state, where ever it is grown especially during summer when there is scarcity of fodder. Leaves of mahua are used for making of plates, cups and donnas on which food is served during festival and other social gathering in rural and tribal area. The chemical constituents of mahua leaves are given in following table.

Table 3: Show the properties and constituents

\begin{tabular}{|c|c|c|}
\hline Sr. No. & Properties & Constituents (\%) \\
\hline 1 & Crude protein & $9.4-10.02$ \\
\hline 2 & Digestible crude protein & 0.03 \\
\hline 3 & Total digestible nutrients & 37.04 \\
\hline 4 & Crude fibre & $19.5-0.35$ \\
\hline 5 & Calcium & 1.66 \\
\hline 6 & Phosphorus & $0.1-0.2$ \\
\hline
\end{tabular}

(Kureel et al., 2009) $^{[13]}$.

3) Uses for soil conservation and soil improvement: Mahua has capability to grow well in saline and alkali soil soils with high $\mathrm{pH}$ value. This can also be grown in the soil with very low organic contents. A root of mahua goes deeper in soil hence it can penetrate and break hard pans of carbamate salts in the subsoils.

4) Uses of flower: Flower is used for fresh consumption, as they are rich source of sugars. Flower also contains vitamin and calcium. Fresh flower and dried one contain 21 to 25 percent and 55 to 58 percent sugar, respectively. Vitamin C, @ 30 to $60 \mathrm{mg}$ per 100 gram and mineral matter 0.8 to 1.5 percent are also present in fresh flower. Mahua flowers have been traditionally used for eating purpose in rural as well as tribal area in form of different recipes.

5) Mahua Stem barks: The stems of mahua are used for the treatment of debility, diabetes, snake-bite, arthritis, tuberculosis, cholera, paralysis, low semen count, tonsillitis, influenza, piles and sinusitis. Flowers are efficient tonic and cooling agent. Leaves help to cure chronic bronchitis, Cushing's disease and eczema. Mahua bark is used to cure itching, inflammation, diabetes and also as an antidote I snake-bite poisoning and as blood purifier (Shrivastava et al., 2014).

\section{Conclusion}

Mahua tree is an integral part of the livelihoods of the tribes and it is most critical and principal suppliers for livelihood. Mahua is a multipurpose use it is fulfilling all the basic need of tribal and rural people in the form of $3 \mathrm{~F}$ i.e. feed, fodder and fuel. However, there is limited availability and marketing of mahua products with very short time span only. Due to unavailability of infrastructure, value addition, preservation and marketing of mahua products as result quality of the flower, fruit and seed are getting deteriorated because of the traditional practices followed by tribal people for its preservation.

It is still untouched by the processors, researchers and consumers beside those places and particular time. To overcome this issue wide scope of commercial utilization of mahua flowers, fruit, seed and oil with advance technology for value addition for production of valuable products with their availability throughout the year by providing infrastructures, storage and marketing facility in tribal and rural areas.

This will absolutely help in upliftment of rural and tribal people economy and their sustainable development. According to scientists, medicines obtained from medicinal plants are best alternative to combat the diseases, as they have immense potential to treat the diseases with least side effect and with high safety and efficacy. All parts of plants had been used in the prevention and treatment for antidiabeties, antibacterial, anticancer, antibacterial, antimicrobial, antioxidant, wound healing activity etc.

The Mahua tree is beneficial for animals for supplying nutritive fodder. Leaves and cake formed after oil extraction is used as animal food as well as fertilizer. Oil obtained from seeds of mahua tree can be used as potential biodiesel source in rural areas and contribute towards attaining selfsufficiency. Oil cake also use as good soil amendment. A development of efficient technologies and awareness among the tribal people will definitely help in improving the quality attributes of the flower which may help in enhancement of employment and income of those societies.

\section{References}

1. Agrawal S, Kulkarni GT, Sharma VN. Antimicrobial and anti-inflammatory activities of bark of four plant species from Indian origin. Webmed Central Pharma Sci 2012;3(10).

2. Awasthi YC, Bhatnagar SC, Mitra CR. Chemurgy of Sapotaceous plants: Madhuca species of India. Econ. Bot 1975;29:380-389. 
3. Behl PN, Sriwasrawa GS. Herbs Useful In Dermatological Therapy, CBS Publishers and Distributors, New Delhi, Edition 2002;2:94-95.

4. Benerji DSN, Rajini K, Rao B Srinivasa. Studies on Physico-Chemical and Nutritional Parameter for the Production of Ethanol from mahua Flower Using Saccharomyces Cerevisiae-3090 through Submerged Fermentation. Journal of Microbial and Biochemical Technology 2010;2:46-50.

5. Gaikwad RD, Ahmed ML, Khalid MS, Swamy P. Antiinflammatory activity of Madhuca longifolia seed saponin mixture. Pharm biol 2009;47(7):592-597.

6. Gupta A, Chaudhary R, Sharma S. Potential applications of mahua (Madhuca indica) biomass. Waste and Biomass Valorization 2012;3(2):175-189

7. Gupta A, Chaudhary R, Sharma S. Potential applications of mahua (Madhucaindica) biomass. Waste and Biomass Valorization 2012;3(2):175-189.

8. Jayasree B, Harishankar N, Rukmini C. Chemical composition and biological evaluation of mahua flowers. J. Oil Technol. Assoc 1998;30:170-72.

9. Jha D, Mazumder P. Biological, chemical and pharmacological aspects of Madhuca longifolia, Asian Pacific Journal of Tropical Medicine 2018.

10. Kalaivani M, Jegadeesan M. Evaluation of antiulcer activity of ethanolic extract of Madhuca longifolia flowers in experimental rats. Int. J Sci Res Publication 2013;3(6):1-7.

11. Kalaivani M, Jegadeesan. Antimicrobial activity of microbial extract of leaves and flower of Madhuka longifolia, International Journal of Scientific and Research Publications 2013;3(5).

12. Kaul S, Kumar A, Bhatnagar AK, Goyal HB, Gupta AK. Biodiesel: a clean and sustainable fuel for future. Scientific strategies for production of non-edible vegetable oils for use as biofuels. All India Seminar on National Policy on Non-Edible oils as Biofuels. Sutra, IISc, Bangalore, India 2003.

13. Kureel RS, Kishore R, Dutta D, Pandey A. Mahua: A potential tree borne oilseed. National Oilseeds and Vegetable Oils Development Board, Ministry of Agriculture, Govt. of India, Gurugaon 2009.

14. Mishra Sunita, Padhan Sarojini-Madhuca Lonigfolia (Sapotaceae): A Review of Its Traditional Uses and Nutritional Properties International Journal of Humanities and Social Science Invention 2012(5):30-36.

15. Mohod SM, Bodhankar SL. Evaluation of antiulcer activity of methanolic extract of leaves of Madhuca indica JF Gmel in rats. Pharmacol online 2011;3:203213.

16. Patel M, Naik SN. Biochemical investigations of fresh mahua (Madhuca indica) flowers for nutraceutical. PhD. Thesis, Centre for Rural Development and Technology, Indian Institute of Technology, New Delhi, India 2008.

17. Patel Madhumita, Naik SN. Flowers of Madhuca Indica J.F. Gmel: Present Status And Future Perspectives. Indian journal of Natural Products and Resources 2010;1:438-443

18. Roy SP, Shirode D, Patel T, Shastry CS, Gheewala N, Sonara G, et al. Antioxidant and hepatoprotective activity of Madhuca longifolia (Koenig) bark against CCl4induced hepatic injury in rats. Biomed Res 2010;1(1):110 .

19. Sharma S, Sharma MC, Kohli DV. Wound healing activity and formulation of ether-benzene-95\% ethanol extract of herbal drug Madhuca longifolia leaves in albino rats. J Optoelectronics Biomed Mater 2010;1(1):13-15.

20. Singh VS, Mishra J Singh, Rai A. Phenolic content and antioxidant activity of solvent extracts, of mahua (Madhuca longifolia) flowers and fruit Nutrafood, 2018.

21. The wealth of India, Raw Material, Council of Scientific and Industrial Research, New Delhi 2007, Vol. 6.

22. Troup RS. The silvicuture of Indian Trees: Vol. II Oxford University Press, Oxford 1921, 640-646. 